\title{
Persepsi Manajemen Kualitas Di Perguruan Tinggi (Studi pada Universitas Sangga Buana YPKP)
}

\author{
Hayun Setiawan \\ Dosen Program Studi Administrasi Bisnis \\ Universitas Sangga Buana YPKP Bandung \\ hayuns@usbypkp.ac.id
}

\begin{abstract}
ABSTRAK
Kerangka kerja Malcom Baldridge memberdayakan lembaga pendidikan untuk mencapai Visi, meningkatkan keluaran, dan menjadi lebih kompetitif. Kerangka kerja terdiri dari Kriteria, nilai-nilai inti dan konsep, dan pedoman penilaian. Kuesioner disusun didasarkan pada tujuh Kriteria Baldrige untuk kategori Kinerja Unggul, yang merupakan bagian dari kerangka kerja Malcom Baldridge. Kuisioner ini mengidentifikasi peluang untuk perbaikan untuk melakukan perbaikan dan mengenali peluang untuk inovasi. Kuisioner mengidentifikasi persepsi para pemimpin senior dan tenaga kerja. Hasilnya akan menantang lembaga pendidikan untuk mengatasi masalah penting bagi keberhasilan lembaga pendidikan.
\end{abstract}

Kata Kunci: Kerangka kerja Baldridge, Pemimpin Senior, Tenaga Kerja

\begin{abstract}
The Malcom Baldridge framework empowers educational institutions to reach it goals, improve results, and become more competitive. The framework consists of the Criteria, the core values and concepts, and the scoring guidelines. The questionnaires are organized by the seven Baldrige Criteria for Performance Excellence categories, part of the Baldrige Excellence Framework. These questionnaires identify opportunities for improvement for making improvements and recognizing opportunities for innovation. The questionnaires ask senior leaders and the workforce. It will challenge the educational institution to address issues critical to educational institutions success.
\end{abstract}

Keywords: Baldridge framework, senior leaders, the workforce. 


\section{PENDAHULUAN}

Lingkungan yang sangat kompetitif saat ini mengajak semua civitas akademika membuat keputusan yang tepat sangat penting. Lembaga pendidikan yang berwujud universitas terdiri dari unsur pimpinan dan unsur anggota yang terdiri dari dosen dan tenaga kependidikan.

Keberhasilan lembaga pendidikan sangat bergantung kepada kesamaan persepsi antara unsur pimpinan, yang terdiri badan penyelenggara, Rektor dan para Wakil Rektor dengan dibantu oleh struktural pelaksanaan teknis operasional dalam menjalankan proses tridharma perguruan tinggi (Pendiidkan, Penelitian dan Pengabdian). Di lain sisi adalah persepsi tenaga kerja sebagai pelaksanaan tugas teknis operasional lembaga pendidikan yang dilaksanakan oleh para dosen dan tenaga kependidikan.

Perbedaan persepsi atas proses manajemen dan rencana hasil (keluaran) yang bertumpu pada Visi, adalah hal yang mustahil untuk diraih. Kerangka kerja Malcom Baldrige untuk lembaga pendidikan memberikan pedoman dalam mengidentifikasi persepsi unsur pimpinan senior dan tenaga kerja melalui kuesioner yang didasarkan pada 7(tujuh) kriteria Malcom Baldrige.

\section{TINJAUAN PUSTAKA}

Tujuh kriteria yang terdapat dalam Malcolm Baldrige adalah kepemimpinan, perencanaan strategis, fokus pada pelanggan, pengukuran, analisis dan manajemen pengetahuan, fokus pada sumber daya manusia, pengelolaan proses, hasil institusi yang digambarkan dalam Kerangka kerja Baldrige. (Gambar.1 Tujuh Kriteria Malcom Baldrige). Untuk mengidentifikasi persepsi Pimpinan Senior dan Tenaga Kerja pada organisasi menggunakan kuesioner yang di download dari nist.gov, yaitu Tool to Quickly Assess Your Leaders' Perceptions dan Tool to Quickly Assess Your Employees' Perceptions. Modifikasi dilakukan dengan disesuaikan kebutuhan.

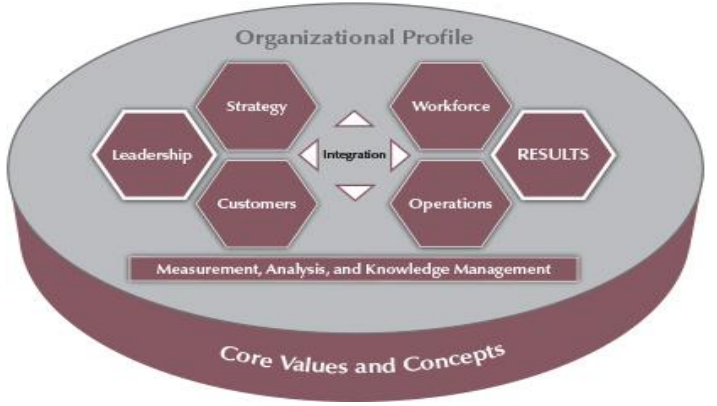

Gambar. 1 Tujuh Kriteria Malcom Baldrige

Ada 40 pernyataan, untuk setiap pernyataan, ditandai memilih yang paling cocok, (sangat tidak setuju, tidak setuju, ragu-ragu, setuju, sangat setuju). Bagaimana persepsi responden akan membantu kami memutuskan aspek apa yang perlu meningkatkan atau mengubah. Waktu pengisian kuesioner sekitar 10-15 menit. Untuk membandingkan persepsi pimpinan senior dengan tenaga kerja, adalah untuk melihat apakah ada perbedaan.

\section{METODOLOGI}

Universitas Sangga Buana YPKP sebagai objek penelitian dengan asumsi Pimipinan Senior adalah Pengurus Yayasan Pendidikan Keuangan dan Perbankan (YPKP) dan Rektor beserta para Wakil Rektor. Sedangkan tenaga kerja adalah pejabat Struktural dibawah Rektorat/Wakil Rektor, Fakultas/Program Studi, Para Dosen Tetap dan Karyawan/Tenaga Kependidikan. Sample responden diambil sebanyak 30\% dari Pimpinan Senior dan Tenaga Kerja.

Metodologi penelitian berisi langkah langkah yang akan dilakukan. Langkah langkah dalam melakukan penelitian dapat dilihat pada Gambar.2. 


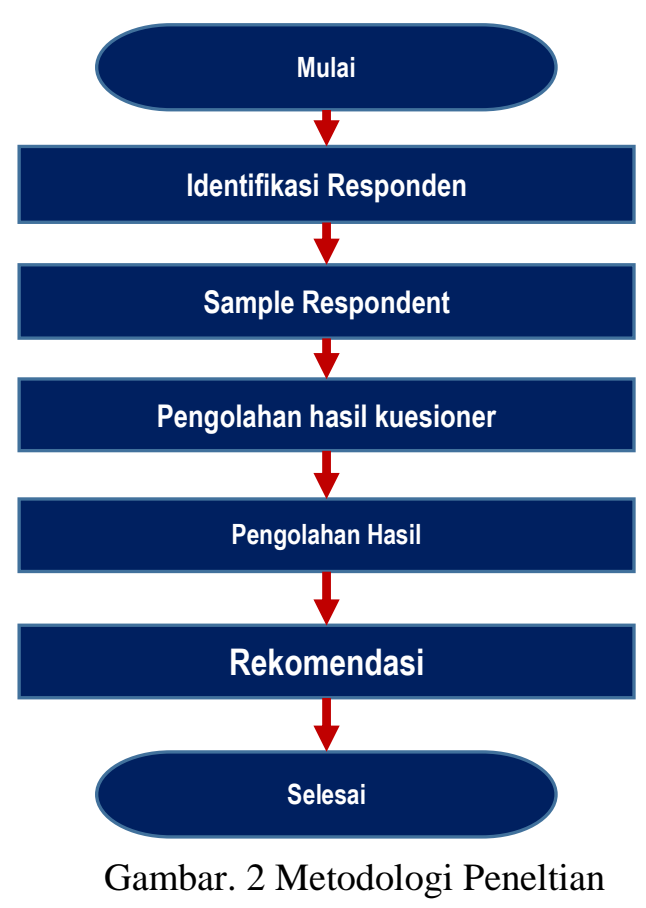

\section{HASIL DAN PEMBAHASAN}

Data hasil persepsi responden yang sangat setuju dan setuju atas pernyataan yang mewakili masing-masing kriteria disajikan pada tabel 1. Terlihat bahwa secara keseluruhan persepsi pimpinan senior dan tenaga kerja menunjukkan dari semua kriteria baru mencapai $50 \%$, artinya pengelolaan proses dan evaluasi hasil yang telah dilaksanakan.

\section{Kriteria Leadership (Kepemimpinan)}

Tenaga kerja mempersepsikan bahwa aspek kepemimpinan baru 52\% dilaksanakan, sedangkan dari pimpinan senior mempersepsikan bahwa sudah cukup $(72 \%)$ aspek kepemimpinan telah dilaksanakan.

\section{Kriteria Strategy (Strategi)}

Tenaga kerja mempersepsikan bahwa aspek implementasi strategi baru $40 \%$ dilaksanakan, sedangkan dari pimpinan senior mempersepsikan bahwa sudah cukup (70\%) aspek strategi telah dilaksanakan.

\section{Kriteria Customers (Pelanggan)}

Tenaga kerja mempersepsikan bahwa aspek implementasi pengelolaan pelanggan $58 \%$ dilaksanakan, sedangkan dari pimpinan senior mempersepsikan hampir sama sekitar 57\% aspek pengelolaan pelanggan. Ini menunjukkan bahwa pengelolaan pelayanan kepada pelanggan belum optimal dilakukan.

Kriteria Measurements, Analysis, and Knowledge Management (Pengukuran Kinerja)

Tenaga kerja dan pimpinan senior mempersepsikan sama (53\%) bahwa aspek implementasi pengukuran kinerja dan manajemen pengetahuan diimplementasikan.

\section{Kriteria Workforce (Sumber Daya Manusia)}

Tenaga kerja mempersepsikan bahwa aspek implementasi strategi pengelolaan sumberdaya manusia baru $54 \%$ dilaksanakan, sedangkan dari pimpinan senior mempersepsikan bahwa sudah baik $(81 \%)$ aspek penglolaan sumberdaya manusia telah dilaksanakan.

\section{Kriteria Process (Proses Kerja)}

Tenaga kerja mempersepsikan bahwa aspek proses kerja $45 \%$ dilaksanakan, sedangkan dari pimpinan senior mempersepsikan bahwa sudah cukup $(63 \%)$ aspek proses kerja telah dilaksanakan.

\section{Kriteria Results Kerja/Keluaran)}

Tenaga kerja mempersepsikan bahwa aspek evaluasi hasil kerja (keluaran) $45 \%$ dilaksanakan, sedangkan dari pimpinan senior mempersepsikan bahwa sudah cukup (69\%) aspek evaluasi hasil kerja telah dilaksanakan. 
Tabel 1.

Persepsi Pimpinan Senior Dan Tenaga Kerja Tentang Manajemen Kualitas Di Perguruan Tinggi

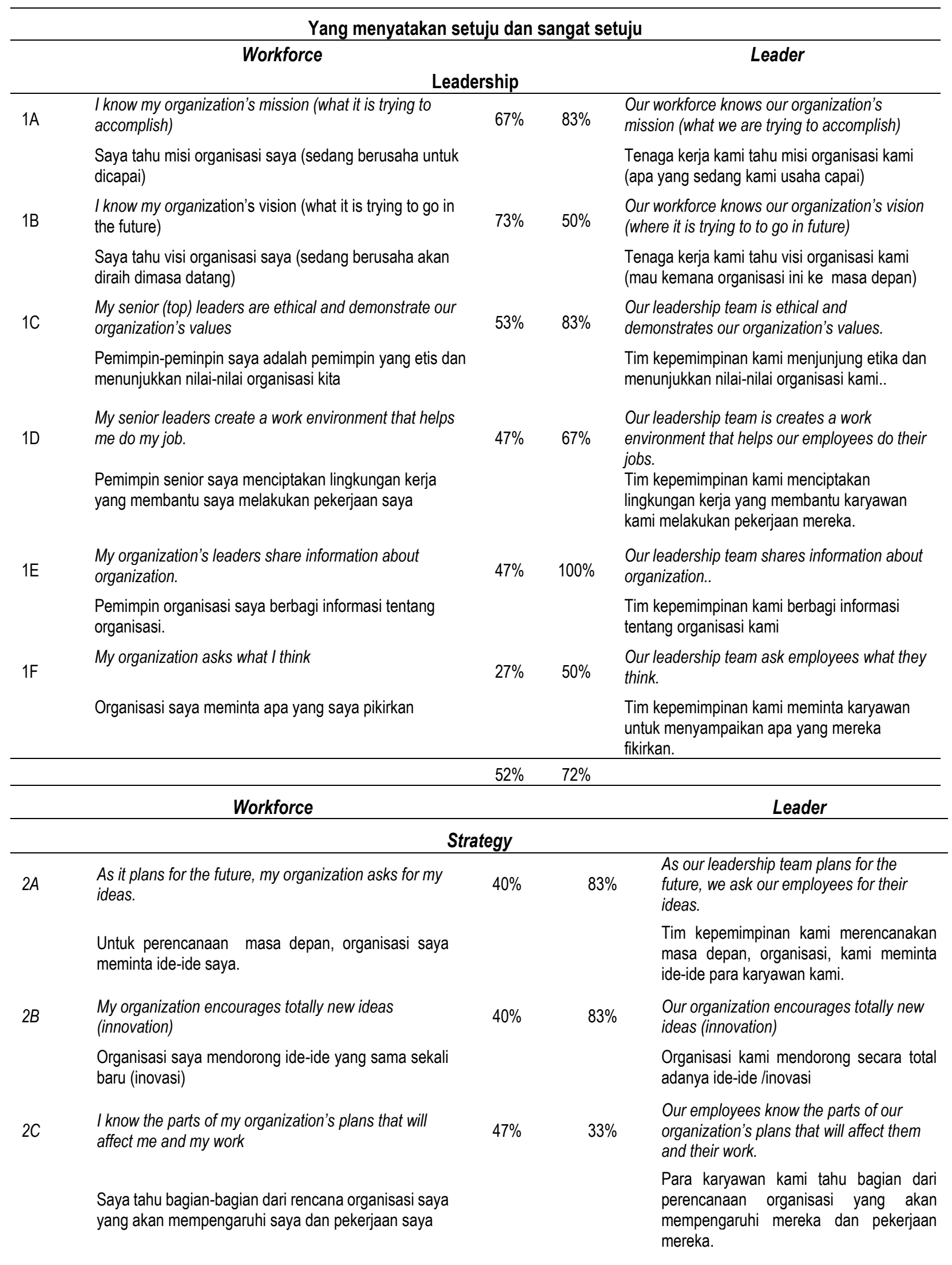



workgroup's part of the plan

$47 \%$

$83 \%$

Saya tahu bagaimana menjelaskan perkembangan pekerjaan kelompok kerja kami dalam membuat kemajuan sebagai bagian dari perencanaan.

$2 E$

My organization is flexible and makes changes quickly when we need.

$27 \%$

$67 \%$

Organisasi saya adalah fleksibel dan membuat perubahan cepat ketika kami membutuhkannya.
2D I know how to tell if we are making progress on my

Our employees know how to tell if they are making progress on their workgroup's part of the plan

Para karyawan kami tahu bagaimana menceritakan jika mereka sedang dalam proses kerja kelompok sebagai bagian dari perencanaan.

Our organization is flexible and makes changes quickly when needed.

Organisasi kami fleksibel dan membuat perubahan cepat ketika dibutuhkan.

\begin{tabular}{|c|c|}
\hline & Workforce \\
\hline \multirow[t]{2}{*}{$3 A$} & I know who my most important customers are. \\
\hline & Saya tahu siapa pelanggan saya yang paling pentir \\
\hline \multirow[t]{2}{*}{$3 B$} & $\begin{array}{l}\text { I regularly ask my customers what they need and } \\
\text { want }\end{array}$ \\
\hline & $\begin{array}{l}\text { Saya secara teratur meminta pelanggan saya apa } \\
\text { yang mereka butuhkan dan inginkan }\end{array}$ \\
\hline \multirow[t]{2}{*}{$3 C$} & $\begin{array}{l}\text { I ask if my customers are satisfied or dissatisfied wi } \\
\text { my work }\end{array}$ \\
\hline & $\begin{array}{l}\text { Saya menanyakan apakah pelanggan saya puas a } \\
\text { tidak puas dengan pekerjaan saya }\end{array}$ \\
\hline \multirow[t]{2}{*}{$3 D$} & $\begin{array}{l}\text { I am allowed to make decisions to satisfy my } \\
\text { customers. }\end{array}$ \\
\hline & $\begin{array}{l}\text { Saya diizinkan dalam membuat keputusan untuk } \\
\text { memuaskan pelanggan saya. }\end{array}$ \\
\hline $3 E$ & $\begin{array}{l}\text { I also know who my organization's most important } \\
\text { customers are. }\end{array}$ \\
\hline
\end{tabular}

Saya juga tahu siapa pelanggan organisasi saya yang paling penting

Leader

\section{Customers}


Saya tahu bagaimana ukuran yang saya gunakan dalam pekerjaan saya dan sesuai dengan ukuran keseluruhan organisasi dalam meningkatkan perbaikan.

$4 D$

$$
\text { I get all the important information I need to do my }
$$
work.

Saya mendapatkan semua informasi penting yang saya butuhkan untuk melakukan pekerjaan saya.

$4 E$

I know how my organization as whole is doing.

$40 \%$

$83 \%$

Saya tahu bagaimana sedang dilakukan organisasi saya secara keseluruhan.
Para karyawan kami tahu bagaimana ukuran yang saya gunakan dalam pekerjaan mereka dan sesuai dengan ukuran keseluruhan organisasi dalam meningkatkan perbaikan.

Our employees get all the important information they need to do their work.

Para karyawan kami mendapatkan semua informasi penting yang merka butuhkan untuk melakukan pekerjaannya.

Our employees know how our organization as whole is doing.

Para karyawan kami tahu bagaimana organisasi kami lakukan operasional secara keseluruhan.

\begin{tabular}{ll}
\hline & Workforce \\
\hline $5 A \quad$ The people I work with corporate and work as a team. \\
\\
$\begin{array}{l}\text { Orang-orang yang bekerja dengan perusahaan dan } \\
\text { saya, bekerja sebagai sebuah tim. }\end{array}$ \\
$5 B \quad \begin{array}{l}\text { My bosses encourage me to develop my job skills so I } \\
\text { can advance in my career. }\end{array}$
\end{tabular}

$53 \% \quad 53 \%$

Workforce

Bos saya mendorong saya untuk mengembangkan

5C I am recognized for my work.

5D I have a safe workplace.

\begin{tabular}{ll}
\hline & Workforce \\
\hline $6 A \quad$ I can get everything I need to do my job. \\
\\
$\begin{array}{l}\text { Saya bisa mendapatkan semua yang saya butuhkan } \\
\text { untuk melakukan pekerjaan saya. }\end{array}$
\end{tabular}

\section{Leader} keterampilan pekerjaan saya sehingga saya bisa maju dalam karir saya.

Saya diakui untuk pekerjaan saya.

Saya memiliki tempat kerja yang aman.

My bosses and my organization care about me

Bos saya dan organisasi saya peduli tentang saya

I am committed to my organization's success

Saya berkomitmen untuk keberhasilan organisasi saya
$40 \%$ $50 \%$

$40 \% \quad 67 \%$

$80 \%$

$53 \%$
Our employees corporate and work as a team.

Para karyawan kami bekerja sama dan bekerja sebagai sebuah tim.

Our leadership team encourage and enables our employees to develop their job skills so they can advance in their career.

Tim kepemimpinan kami mendorong para karyawan untuk mengembangkan keterampilan pekerjaannya sehingga mereka bisa maju dalam karirnya.

Our employees are recognized for their work.

Para karyawan kami diakui untuk pekerjaannya.

Our organization has a safe workplace. Organisasi kami memiliki tempat kerja yang aman.

Our managers and our organization care about our workforce

Para manajer kami dan organisasi peduli tentang para karyawan.

Our employees are committed to their organization's success

Para karyawan kami berkomitmen untuk keberhasilan organisasinya.

$54 \% \quad 81 \%$

\section{Operation}

$20 \%$

$50 \%$
Kami memiliki proses yang baik untuk melakukan pekerjaan kami.
Leader

Our employees can get everything they need to do their job.

Para karyawan kami bisa mendapatkan semua yang mereka butuhkan untuk melakukan pekerjaannya. doing its work.

Organisasi kami memiliki proses yang baik untuk melakukan pekerjaannya.
Our organization has good processes for 
6C I can improve my work processes when necessary

Saya dapat meningkatkan proses kerja saya ketika diperlukan

$6 D \quad$ We are prepared to handle an emergency

Kami siap untuk menangani keadaan darurat
$60 \% \quad 83 \%$

$60 \% \quad 67 \%$
Our employees can improve their work processes when necessary

Para karyawan kami dapat meningkatkan proses kerjanya ketika diperlukan

Our organization is prepared to handle an emergency

Organisasi kami siap untuk menangani keadaan darurat

\begin{tabular}{|c|c|c|c|c|}
\hline & $45 \%$ & \multirow{2}{*}{\multicolumn{2}{|c|}{ Leader }} \\
\hline & Workforce & & & \\
\hline \multicolumn{5}{|c|}{ Results } \\
\hline $7 A$ & My work product meet all requirements. & $47 \%$ & $50 \%$ & $\begin{array}{l}\text { Our employees work product meet all } \\
\text { requirements. }\end{array}$ \\
\hline & $\begin{array}{l}\text { Produk pekerjaan saya memenuhi semua } \\
\text { persyaratan. }\end{array}$ & & & $\begin{array}{l}\text { Produk pekerjaan para karyawan kami } \\
\text { memenuhi semua persyaratan. }\end{array}$ \\
\hline \multirow[t]{2}{*}{$7 B$} & My customer are satisfied with my work & $67 \%$ & $50 \%$ & $\begin{array}{l}\text { Our employees customer are satisfied with } \\
\text { their work }\end{array}$ \\
\hline & Pelanggan saya puas dengan pekerjaan saya & & & $\begin{array}{l}\text { Pelanggan para karyawan kami puas dengan } \\
\text { pekerjaannya. }\end{array}$ \\
\hline \multirow[t]{2}{*}{$7 C$} & I know how well my organization is doing financially. & $33 \%$ & $33 \%$ & $\begin{array}{l}\text { Our employees know how well our } \\
\text { organization is doing financially. }\end{array}$ \\
\hline & $\begin{array}{l}\text { Aku tahu seberapa baik organisasi saya lakukan } \\
\text { secara finansial. }\end{array}$ & & & $\begin{array}{l}\text { Para karyawan kami tahu seberapa baik } \\
\text { organisasinya mengelola aspek keuangannya. }\end{array}$ \\
\hline \multirow[t]{2}{*}{$7 D$} & $\begin{array}{l}\text { My organization has the right people and skills to do } \\
\text { its work. }\end{array}$ & $27 \%$ & $67 \%$ & $\begin{array}{l}\text { Our organization has the right people and } \\
\text { skills to do its work. }\end{array}$ \\
\hline & $\begin{array}{l}\text { Organisasi saya memiliki orang yang tepat dan } \\
\text { keterampilan untuk melakukan tugasnya. }\end{array}$ & & & $\begin{array}{l}\text { Organisasi kami memiliki orang yang tepat } \\
\text { dan keterampilan untuk melakukan tugasnya. }\end{array}$ \\
\hline \multirow[t]{2}{*}{$7 E$} & $\begin{array}{l}\text { My organization removes things that get in the way of } \\
\text { progress }\end{array}$ & $27 \%$ & $83 \%$ & $\begin{array}{l}\text { Our organization removes things that get in } \\
\text { the way of progress }\end{array}$ \\
\hline & $\begin{array}{l}\text { Organisasi saya menghilangkan hal-hal yang } \\
\text { menghalangi kemajuan }\end{array}$ & & & $\begin{array}{l}\text { Organisasi kami menghilangkan hal-hal yang } \\
\text { menghalangi kemajuan }\end{array}$ \\
\hline $7 F$ & $\begin{array}{l}\text { My organization obey laws and regulations. } \\
\text { Organisasi saya mematuhi hukum dan peraturan. }\end{array}$ & $60 \%$ & $83 \%$ & $\begin{array}{l}\text { Our organization obey laws and regulations. } \\
\text { Organisasi kami mematuhi hukum dan } \\
\text { peraturan. }\end{array}$ \\
\hline \multirow[t]{2}{*}{$7 G$} & My organization practices high standards and ethics. & $67 \%$ & $83 \%$ & $\begin{array}{l}\text { Our organization practices high standards } \\
\text { and ethics. }\end{array}$ \\
\hline & $\begin{array}{l}\text { Organisasi saya mempraktekan standar yang tinggi } \\
\text { dan etika. }\end{array}$ & & & $\begin{array}{l}\text { Organisasi kami mempraktekan standar yang } \\
\text { tinggi dan etika. }\end{array}$ \\
\hline \multirow[t]{2}{*}{$7 H$} & My organization helps me help my community. & $53 \%$ & $83 \%$ & $\begin{array}{l}\text { Our organization helps our employees help } \\
\text { their community. }\end{array}$ \\
\hline & $\begin{array}{l}\text { Organisasi saya membantu saya,membantu } \\
\text { komunitas saya. }\end{array}$ & & & $\begin{array}{l}\text { Organisasi kami membantu para karyawannya } \\
\text { dan,membantu komunitasnya. }\end{array}$ \\
\hline \multirow[t]{2}{*}{71} & My organization is a good place to work. & $53 \%$ & $83 \%$ & Our organization is a good place to work. \\
\hline & $\begin{array}{l}\text { Organisasi saya adalah tempat yang baik untuk } \\
\text { bekerja. }\end{array}$ & & & $\begin{array}{l}\text { Organisasi kami adalah tempat yang baik } \\
\text { untuk bekerja. }\end{array}$ \\
\hline
\end{tabular}




\section{KESIMPULAN}

1. Pimpinan senior hendaknya mengkaji kembali Visi institusi dan proses deseminasinya sehingga semua anggota organisasi memahaminya.

2. Pimpinan senior hendaknya mengajak seluruh anggota organisasi untuk berubah sesuai tuntutan lingkungan strategis yang semakin kompetitif (keluar dari zona nyaman)

3. Peningkatan pelayanan kepada pemangku kepentingan sudah harus segera dilakukan, terutama peningkatan layanan kepada mahasiswa melalui kolaborasi internal organisasi.

4. Penilaian Kinerja perlu dilakukan perbaikan dan kejelasan tindak lanjut evaluasi kinerja.

5. Pengelolaan Sumber Daya Manusia, khususnya peningkatan pengembangan dan fasilitas.

6. Penyusunan kembali Standar Operating Procedure (SOP).

7. Tindak lanjut hasil dan focus kepada peningkatan profesionalisme.

\section{DAFTAR PUSTAKA}

The Malcom Baldridge framework for Performance Excellence, 2017-2018, http://www.nist.gov/baldrige.

Pudjo Sumedi AS, Berbagai Modul Sistem Mutu dan Penerapannya Dalam Dunia Pendidikan, Education Indonesia, Volume 16, Nomor 1, Juni 2008. 